\title{
Special Issue on Social Media
}

\author{
Detlef Schoder • Peter A. Gloor • \\ Panagiotis Takis Metaxas
}

Published online: 10 January 2013

(C) Springer-Verlag Berlin Heidelberg 2012

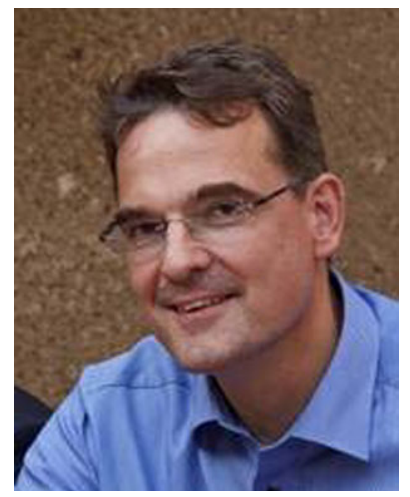

Detlef Schoder

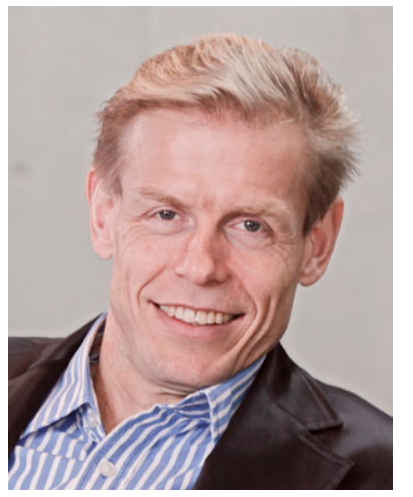

Peter A. Gloor

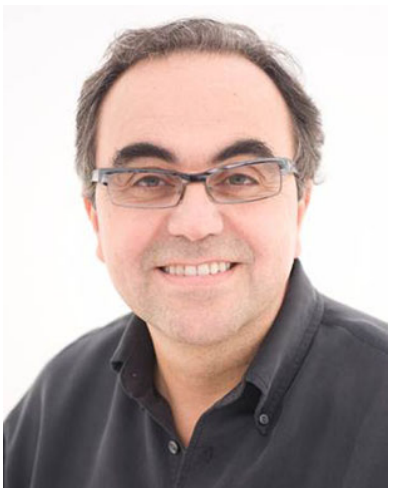

Panagiotis Takis Metaxas
This special issue includes papers that show, first, how to make sense of Social Media data, i.e. how to condense, distill, or integrate highly decentralized and dispersed data resulting from human communication, and second, how Social Media contributes to innovation, collaboration, and Collective Intelligence.

\section{Schoder $(\bowtie)$}

Dept. of Information Systems and Information Management and Institute of Broadcasting Economics, University of Cologne (Köln), Cologne, Germany

e-mail: schoder@wim.uni-koeln.de

\section{P.A. Gloor}

Center for Collective Intelligence, MIT Sloan School

of Management, Cambridge, MA, USA

e-mail: pgloor@mit.edu

\section{P.T. Metaxas}

Dept. of Computer Science, Wellesley College, Boston, MA, USA

\section{P.T. Metaxas}

Center for Research on Computation and Society, Harvard

University, Cambridge, MA, USA

e-mail: pmetaxas@seas.harvard.edu
We selected papers covering diverse aspects of Social Media analysis including Social Media in business, entertainment, as well as in art. We invited insightful artifacts and methods as well as analytical, conceptual, empirical, and theoretical approaches (using a wide range of research methods, including experiments, primary data from Social Media logs, case studies, simulations, surveys, and so on). We provided a list of topics including information and Web mining (e.g. opinion mining); prognosis (e.g. trend and hot topic identification); Collective Intelligence; crowdsourcing; swarm creativity, collaborative innovation networks; (dynamic) Social Media monitoring; sentiment and natural language processing; Social Media within and for smart cities, smart traffic, smart energy; social networks for the collaboration of large communities; user behavior, social interaction; social network analysis (SNA), semantic network analysis; social search engines and aggregators; social network games; personalization and adaptation to user preference; trust, reputation, social control, privacy; information reliability, Web spam, and content authenticity (e.g., detecting "astroturfing"). 
This special issue attracted eleven submissions out of which we selected three full research papers. Given the editorial directives by the editorial board we complemented the special issue with a survey paper, a project description, two interviews, a tutorial, and two reports on completed doctoral theses.

In order to ensure highest reviewing standards and to avoid bias we asked qualified, independent external reviewers to review all submissions. After initial screening all papers submitted were reviewed in the first round by at least three reviewers (with one exception: for one paper-a clear reject - the review process was shortened). Three author teams were invited to revise their manuscripts according to the reviews. A final check by those guest editors who were not co-authors of any submission ensured that the appropriate steps were taken so that the papers could be further handled by the editors of Künstliche Intelligenz.

The opener is an overview article by the guest editors of this special issue, in which we focus on the constituting attributes of Social Media and Collective Intelligence, we structure the rapidly growing body of research at the intersection of Social Media and Collective Intelligence, and conclude with some propositions for further research.

In the second article, "Learning to Discover Political Activism in the Twitterverse", Samantha Finn and Eni Mustafaraj study political discussions on Twitter. They propose a supervised machine learning approach to separate Twitter accounts into two groups: "political activists" and "general public". Incorporating information about classifier probability into the classification, they show that their classifier achieves a high accuracy on single tweets and an even higher accuracy when looking at a larger collection of tweets from a user. With this work the authors show that machine learning algorithms can play a critical role in improving the quality of Social Media analytics and understanding.

The third article, "Can Computers Learn from the Aesthetic Wisdom of the Crowd?" by Christian Bauckhage and Kristian Kersting addresses the interesting topic of teaching an algorithm to recognize the aesthetic appeal of images. By working on a large dataset of tagged images from Flickr, they find that automatic classification of aesthetic appeal is indeed possible based on established low-level image features. Their results have implications for the fields of AI and computer vision as well as Collective Intelligence.

Fourth is an article by Peter A. Gloor, Daniel Oster, and Kai Fischbach titled "JazzFlow_Analyzing 'Group Flow' among Jazz Musicians Through 'Honest Signals"', in which the authors aim to analyze the pre-requisites of "group flow" in self-organizing creative teams. By analyzing data from sociometric badges during a live performance of a group of jazz musicians, they find that "honest signals" play an essential role in enabling the smooth operation of such teams. Their findings hold interesting implications for research in group dynamics and creativity in self-organizing teams not only in music but also in companies relying on creativity and innovation.

Further, we include a project description by Joshua Introne, Robert Laubacher, Gary Olson, and Thomas Malone. In their contribution, "Solving Wicked Social Problems with Socio-computational Systems", they describe how the MIT Climate CoLab project may help in solving global climate change problems while taking advantage of Collective Intelligence and collaborative planning.

We follow with two interviews by major researchers in Social Media and AI. First, is an interview with Prof. James A. Hendler, an artificial intelligence researcher at Rensselaer Polytechnic Institute, USA, and one of the originators of the Semantic Web. He highlights the evolution of current technologies with the help of semantics and the need for agents that can support the development and evolution of social machines. Next, is an interview with Dr. Bernardo Huberman, senior HP Fellow and director of the Social Computing Research Group at HP Labs, where he talks about the opportunities and challenges that come with using Social Media as a data source for research.

In their brief tutorial, Marc Egger and André Lang summarize the process steps needed to analyze Social Media data. Their paper focuses on the challenges that emerge from finding, collecting and analyzing user-generated content from the Web.

We conclude this special issue with summaries of two $\mathrm{PhD}$ dissertations. "Crowd-Powered Systems" by Michael $\mathrm{S}$. Bernstein shows how hybrid systems that combine computation with human intelligence from the crowd enable new applications and experiences. In her $\mathrm{PhD}$ thesis, "From Texts to Networks: Detecting and Managing the Impact of Methodological Choices for Extracting Network Data from Text Data", Jana Diesner addresses methodological problems related to extracting information about networks from text data.

We hope you enjoy reading!

$$
\begin{array}{r}
\text { Detlef Schoder } \\
\text { Peter A. Gloor } \\
\text { Panagiotis Takis Metaxas }
\end{array}
$$

\section{Content}

\subsection{Technical Contributions}

- Social Media and Collective Intelligence-Ongoing and Future Research Streams

Detlef Schoder, Peter A. Gloor, Panagiotis Takis Metaxas

- Learning to Discover Political Activism in the Twitterverse

Samantha Finn, Eni Mustafaraj 
- Can Computers Learn from the Aesthetic Wisdom of the Crowd?

Christian Bauckhage, Kristian Kersting

- JazzFlow-Analyzing "Group Flow" among Jazz Musicians Through "Honest Signals"

Peter A. Gloor, Daniel Oster, Kai Fischbach

\subsection{Research Projects}

- Solving Wicked Social Problems with Socio-computational Systems

Joshua Introne, Robert Laubacher, Gary Olson, Thomas Malone

- A Brief Tutorial on How to Extract Information from User-Generated Content (UGC)

Marc Egger, André Lang

\subsection{Interviews}

- Interview with James A. Hendler (Artificial intelligence researcher at Rensselaer Polytechnic Institute, USA, and one of the originators of the Semantic Web)

- Interview with Bernardo Huberman (Senior HP Fellow and director of the Social Computing Research Group at HP Labs)

\subsection{Doctoral and Postdoctoral Dissertations}

- Crowd-Powered Systems

Michael S. Bernstein

- From Texts to Networks: Detecting and Managing the Impact of Methodological Choices for Extracting Network Data from Text Data

Jana Diesner

\section{Service}

\subsection{Journals}

Journals with a dedicated focus on Social Media include the following:

- ACM Transactions on the Web (TWEB)

http://dl.acm.org/citation.cfm?id=J1062\&CFID= $127959581 \&$ CFTOKEN $=64816588$

- International Journal of Advanced Media and Communication http://www.inderscience.com/jhome.php?jcode=ijamc

- International Journal of Knowledge and Web Intelligence http://www.inderscience.com/jhome.php?jcode=ijkwi

- International Journal of Social Media and Interactive Learning Environments http://www.inderscience.com/jhome.php?jcode=ijsmile
- International Journal of Web Based Communities http://www.inderscience.com/jhome.php?jcode=ijwbc

- International Journal of Web Science http://www.inderscience.com/jhome.php?jcode=ijws

- Social Networks www.journals.elsevier.com/social-networks/

In addition, Social Media related articles are regularly published in journals from the fields of information systems, social network analysis, data mining, and marketing.

\subsection{Books}

There is an ever-increasing body of literature including books on Social Media and collective intelligence. The following short list is a very subjective selection of books, which in particular caught our attention.

- Barabasi, A.-L. (2012) Network Science: An interactive textbook. Published online at http://barabasilab.com/ networksciencebook.

- Benkler, Y. (2007). The Wealth of Networks: How Social Production Transforms Markets and Freedom. Yale University Press.

- Benkler, Y. (2011). The Penguin and the Leviathan-How Cooperation Triumphs over Self-Interest, Random House.

- Dijk, J.A.G.M. van. (2005). The Network Society: Social Aspects of New Media (2nd edition). Sage Publications Ltd.

- Easley, D., \& Kleinberg, J. (2010). Networks, Crowds, and Markets: Reasoning About a Highly Connected World. Cambridge University Press.

- Gloor, P.A. (2006). Swarm Creativity: Competitive Advantage through Collaborative Innovation Networks. Oxford University Press, USA.

- Manning, C., Raghavan, P. and Schütze, H. (2008) Introduction to Information Retrieval, Cambridge University Press.

- McAfee, A. (2009). Enterprise 2.0: New Collaborative Tools for Your Organization's Toughest Challenges. Harvard Business School Press.

- Newman, M. (2010). Networks: An Introduction, Oxford University Press.

- Rainie, L., \& Wellman, B. (2012). Networked: The New Social Operating System. The MIT Press.

- Russell, M.A. (2011). Mining the Social Web. O'Reilly.

- Shirky, C. (2009). Here Comes Everybody: The Power of Organizing Without Organizations (Reprint). Penguin Books.

- Surowiecki, J. (2005). The Wisdom of Crowds, Anchor.

- Tovey, M. (Ed.) (2008): Collective Intelligence. Earth Intelligence Network. 


\subsection{Conferences and workshops}

Conferences with a dedicated coverage of Social Media and/or Collective Intelligence include the following:

- ACM Web Science (WebSci) http://www.sigweb.org/conferences/sigweb-conference/ web-sci

- ACM International Conference on Web Search and Data Mining (WSDM) http://www.wsdm-conference.org/

- Collective Intelligence (CI) http://www.ci2012.org/

- IEEE International Conference on Social Computing (SocialCom) http://www.iisocialcom.org/

- International Conference on Web Information Systems and Technologies (WEBIST) http://www.webist.org/

- International Conference on Weblogs and Social Media (ICWSM) http://www.icwsm.org/

- International Network for Social Network Analysis (INSNA) www.insna.org/

- International World Wide Web Conference (WWW) http://www.iw3c2.org/

In addition, a multitude of conferences in the fields of information systems, social network analysis, data mining, and marketing include tracks on or related to Social Media and Collective Intelligence.

\subsection{Organizations}

Various national and international organizations center around topics connected to Social Media such as the following:

- ACM Special Interest Group on Hypertext and the Web (SIGWEB) http://www.sigweb.org/

- Web Science Trust http://webscience.org/

\subsection{Software}

Some software with a main focus on Social Media analysis are the following:
- Condor computes and visualizes the structure of social communication networks by automatically generating interactive movies of communication flows: http://www.ickn.org/condor.html

- Gephi is an interactive visualization and exploration platform for all kinds of networks and complex systems, dynamic and hierarchical graphs: http://gephi.org/

- NetMiner is a premium software tool for exploratory analysis and visualization of network data. NetMiner allows you to explore your network data visually and interactively, and helps you to detect underlying patterns and structures of the network:

http://www.netminer.com/

- NodeXL is a free, open-source template for Microsoft ${ }^{\circledR}$ Excel $^{\circledR} 2007$ and 2010 that makes it easy to explore network graphs: http://nodexl.codeplex.com/

- Weka is a collection of machine learning algorithms for data mining tasks. The algorithms can either be applied directly to a dataset or called from your own Java code. Weka contains tools for data pre-processing, classification, regression, clustering, association rules, and visualization. It is also well-suited for developing new machine learning schemes: http://www.cs.waikato.ac.nz/ml/weka/

- yEd is a powerful desktop application that can be used to quickly and effectively generate high-quality diagrams: http://www.yworks.com/en/products_yed_about.html

In addition there are many more tools and frameworks stemming mostly from network analysis or machine learning streams that enable the analysis of Social Media data.

Acknowledgements We owe our thanks to many friends, colleagues, and scholars who helped make this special edition possible. First, we are grateful to all the authors of the articles for prompt responses and the members of the editorial review board for timely and thorough reviews. The board included Ioannis Anagnostopoulos, Roman Beck, Alexander Benlian, Sascha Costanza-Chock, James Danowski, JC deMartin, Jana Diesner, Kai Fischbach, Cristobal Garcia, Georg Groh, Julia Gluesing, Bruno Goncalves, Francesca Grippa, Georg Groh, Takashi Iba, Minhyung Kang, Ralf Klamma, Michael Koch, Hong Joo Lee, Yoshiaki Matsuzawa, Eni Mustafaraj, Dimitar Nikolov, Ken Riopelle, Mathias Trier, Michalis Vafopoulos and Matthäus Zylka. We owe special thanks to Johannes Putzke for his contributions to the editorial survey paper and Puja Abbassi, who expediently helped us to manage the review process. We are also thankful to the board of Künstliche Intelligenz, Klaus Althoff (Editor-In-Chief) and Bernd Ludwig for enduring support throughout the whole process and finally to the staff at Springer for realizing this project online and offline. 